\title{
The role of nutritional support in the physical and functional recovery of critically ill patients: a narrative review
}

\author{
Danielle E. Bear ${ }^{1,2,3,4,5^{*}}$, LiesI Wandrag ${ }^{1,2}$, Judith L. Merriweather ${ }^{6}$, Bronwen Connolly, ${ }^{4,5,7,8}$, Nicholas Hart ${ }^{3,4,5 \dagger}$, \\ Michael P. W. Grocott ${ }^{9,10,11 \dagger}$ and on behalf of the Enhanced Recovery After Critical Illness Programme Group \\ (ERACIP) investigators
}

\begin{abstract}
The lack of benefit from randomised controlled trials has resulted in significant controversy regarding the role of nutrition during critical illness in terms of long-term recovery and outcome. Although methodological caveats with a failure to adequately appreciate biological mechanisms may explain these disappointing results, it must be acknowledged that nutritional support during early critical illness, when considered alone, may have limited long-term functional impact. This narrative review focuses specifically on recent clinical trials and evaluates the impact of nutrition during critical illness on long-term physical and functional recovery.

Specific focus on the trial design and methodological limitations has been considered in detail. Limitations include delivery of caloric and protein targets, patient heterogeneity, short duration of intervention, inappropriate clinical outcomes and a disregard for baseline nutritional status and nutritional intake in the post-ICU period. With survivorship at the forefront of critical care research, it is imperative that nutrition studies carefully consider biological mechanisms and trial design because these factors can strongly influence outcomes, in particular long-term physical and functional outcome. Failure to do so may lead to inconclusive clinical trials and consequent rejection of the potentially beneficial effects of nutrition interventions during critical illness.
\end{abstract}

Keywords: Nutrition, Critical illness, Physical recovery, Energy, Protein

\section{Background}

Many basic questions about the provision of nutritional support to critically ill patients remain unanswered [1]. Outcome from critical illness has previously been measured using relatively blunt outcome measure tools such as mortality, days on mechanical ventilation and rates of acquired infection. Recent randomised controlled trials (RCTs) have not shown any mortality benefit when specific nutritional interventions have been investigated over the first week of critical illness [2-4] and other studies have reported harm [5-7]. This has led to useful debate regarding the most appropriate timing, type and

\footnotetext{
* Correspondence: Danielle.Bear@gstt.nhs.uk

tEqual contributors

'Department of Nutrition and Dietetics, Guy's and St Thomas' NHS

Foundation Trust, London, UK

'Department of Critical Care, Guy's and St Thomas' NHS Foundation Trust,

London, UK

Full list of author information is available at the end of the article
}

amount of nutrition support that should be delivered to critically ill patients.

It is generally accepted that providing some enteral nutrition (EN) early (within 48-72 hours of admission) modulates the immune response and reduces oxidative stress and infections by limiting bacterial translocation via the gut $[1,8,9]$. In addition, provision of nutrition over the course of critical illness may alter the composition and function of the host microbiome [10], further influencing the immune response. However, the clinical impact of this physiological observation is unknown. In contrast, it has been hypothesised that early feeding blunts autophagy, preventing adequate clearance of damaged cells and resulting in muscle wasting and increased muscle weakness $[1,7]$.

As the number of patients surviving critical illness has risen, there has been an increase in reported physical and functional disability as well as impairment of quality 
of life following discharge from the intensive care unit (ICU) [11-13]. Body composition and physical and functional impairment have been measured using a variety of tools at different time points over the course of critical illness and the patient's recovery trajectory $[14,15]$. At least 33 different measures of skeletal muscle mass, strength and function have been identified for use in critically ill patients [14]. These measures include both volitional and non-volitional tools, with varying reliability and validity. Currently, the most appropriate measure to use at each time point and for each intervention is unknown. Whichever measure is used, it is clear that recovery in survivors from critical illness is poor, even up to 5 years post discharge from the ICU [13].

Skeletal muscle weakness, termed intensive care unitacquired weakness (ICU-AW), contributes significantly to the physical and functional disability observed in these patients. Skeletal muscle wasting, both early in critical illness [16] and potentially ongoing as a result of persistent inflammatory catabolic syndrome (PICS) [17], has been identified as a contributing factor to ICU-AW [18]. Furthermore, low skeletal muscle mass on admission to the ICU has been shown to be a predictor of poor outcome [19]. It is here, in the reduction of skeletal muscle wasting and the recovery of survivors of critical illness, that nutrition support may prove the most beneficial, but there is remarkably little nutrition research specifically focusing on these outcomes.

The aims of early nutrition support in critically ill patients are often cited as the reduction of catabolism, attenuation of muscle wasting and maintenance of nutritional status $[8,9]$. However, to date there has been limited focus on muscle wasting and functional performance as outcomes in critical care nutrition trials. This narrative review will discuss clinical trials which have evaluated the physical and functional impact of critical care nutrition interventions, either as secondary outcomes, sub-studies or post-hoc analyses, as well as the effect of timing, type and amount of nutrition support on recovery following critical illness. Particular attention will be given to factors that should be considered in the design of future RCTs of nutrition in this patient group, which will probably benefit from adoption of a translational science approach.

\section{Timing of nutrition support}

Most experts and guidelines agree that EN should be commenced within 24-48 hours of admission to the ICU $[1,8,20,21]$. Early EN is encouraged to assist with the maintenance of gut integrity, modulation of the stress and immune response and attenuation of disease severity [22, 23], which may, in turn, improve overall outcome [24]. The most recent meta-analysis of trials investigating the effect of early EN was performed as part of the joint American Society for Parenteral Nutrition (ASPEN) and Society of Critical Care Medicine (SCCM) guidelines for the provision of nutrition support in critical illness [8]. This systematic review identified $21 \mathrm{RCTs}$ meeting their inclusion criteria and found that provision of early EN was associated with a significant reduction in mortality and infectious morbidity compared with withholding early EN (delayed EN or standard care) [8].

In contrast to this convincing evidence, others argue that anorexia may be a preserved evolutionary response and that early starvation or limiting nutritional intake over the first 48-72 hours to the first week of critical illness is beneficial $[25,26]$. This notion contrasts with results of many observational studies reporting that feeding via the enteral route alone leads to significant underfeeding which in turn is negatively associated with the standard outcome measures of mortality, length of stay and infection frequency [27-30]. As a consequence of these findings, the use of $\mathrm{PN}$ has increased over recent years, which raises further questions in relation to the timing of nutrition support.

In the large EPaNIC trial (Early Parenteral Nutrition Completing Enteral Nutrition in Adult Critically Ill Patients) [7], the use of early PN to supplement early insufficient EN led to greater muscle weakness, thought to be related to impaired autophagy [31]. For this reason, the use of PN (either exclusive or supplemental) is not recommended over the first 7 days of ICU admission in patients who are not considered to be at high nutritional risk [8].

Despite these opposing views, studies investigating the impact of withholding nutrition completely over the first week of critical illness do not exist and guidelines continue to recommend increasing nutrition support over the first week of critical illness to meet target recommendations $[8,20,21]$. Additionally, studies undertaken after the first week of critical illness, and indeed in the post-ICU phase, are lacking. This will be discussed later in the review, but essentially the impact of usual nutritional practice in the ICU on the physical and functional recovery of ICU patients is unknown.

The presumed benefit of nutritional support during critical illness, in order to reduce muscle wasting, is based on three assumptions. The first assumption is that all patients absorb all of the nutrients delivered; the second is that the critically ill skeletal muscle can utilise the nutrients which are delivered; and the third assumption is that the consequence of these processes is always an anabolic and never a catabolic effect [32]. Contrary to these assumptions, delays in gastric emptying [33] and incomplete absorption from the small bowel [34] may significantly alter the presumed benefit. In addition, little is known about the ability of skeletal muscle to utilise these nutrients at different time points over the ICU 
admission. It is possible that current feeding methods may not physiologically be able to produce the desired outcome benefit or that provision of nutrients does not result in anabolism, particularly in the earliest phase of critical illness (e.g. first 48-72 hours) [35] or in clinical conditions defined by persistent inflammation and hypoxia [16]. Studies investigating the anabolic effect of nutrition at different time points over the course of critical illness and recovery are required to provide further guidance on the most appropriate timing of nutrition support in order to influence these outcomes.

\section{Dose of nutrition support Energy}

In general, critically ill patients do not meet recommended levels of nutritional intake, particularly when the enteral route is used alone [36]. This is true both in routine clinical practice [36] and in the setting of RCTs [2-4]. The effect of underfeeding during the period of critical illness on skeletal muscle wasting and physical function is wholly unclear. One-year follow-up from the EDEN trial (Early vs Delayed Enteral Feeding to Treat People with Acute Lung Injury or Acute Respiratory Distress Syndrome) suggested that there was no beneficial effect on physical function from target compared with trophic enteral feeding over the first 6 days of critical illness [37], albeit in the context of a number of confounders that would need further consideration. However, more patients in the trophic feeding group were discharged to rehabilitation centres, suggesting that there may be some beneficial effect to improving nutritional intakes [37]. Noteworthy in this trial is that patients in the full feeding group only met $70 \%$ of the energy targets which may not be sufficient to produce an outcome benefit, at least when predictive equations are used [30]. In contrast, a sub-group analysis from the Reducing Deaths due to Oxidative Stress Study (REDOXs) found that increasing nutritional adequacy led to improvements in 3-month Short Form-36 (SF-36) scores relating to the physical domains. However, this effect was diminished by 6 months [38]. Other large RCTs have also included physical or quality of life outcomes with varying results (Table 1) [2, 3, 31, 38-42].

Two pre-planned sub-group analyses from the EPaNIC study investigated the impact of the macronutrient dose (in the form of early vs late supplemental PN) on rates of skeletal muscle wasting [31, 39]. The first of these [31] found that muscle wasting, measured from muscle biopsies, was not different between the two groups. In addition, using the Medical Research Council (MRC) sum-score, weakness was found to recover faster in the group receiving late $\mathrm{PN}$. In the second of these subgroup analyses [39], early $\mathrm{PN}$ was shown to adversely impact on femoral muscle quality, measured using computed tomography (CT) scans, but did not affect the rates of wasting observed in 15 neurosurgical patients.

It is likely that the timing and dose of energy provision go hand in hand. Indeed, recent thinking suggests that consideration of the endogenous production of energy in early critical illness is essential to the timing and dose of nutritional supplementation [1]. However, with no bedside method to measure endogenous energy production, it is impossible to account for this when calculating energy expenditure and devising feeding regimens. It has been postulated that in early critical illness (e.g. within the first 72-96 hours) permissive underfeeding to approximately $15 \mathrm{kcal} / \mathrm{kg}$ with full protein nutrition support may be warranted [43], but this awaits confirmation of benefit in RCTs. In addition, the use of predictive equations to determine energy targets may heavily influence the results of nutrition trials in the ICU as they are known to produce results which are less accurate than measured energy expenditure (MEE) using indirect calorimetry [44]. Indeed, studies feeding to MEE have consistently shown positive benefits and a recent observational study found that feeding to $70 \%$ of MEE was optimal in terms of mortality [45]. However, limitations preclude the frequent use of indirect calorimetry in clinical practice. These include availability of accurate metabolic monitors, costs, time taken to undertake the measurement and specific exclusions meaning that some of the sickest patients are unsuitable for measurement (e.g. those on continuous renal replacement therapy and those with high oxygen requirements) [46]. However, the introduction to the market of a metabolic monitor designed specifically for mechanically ventilated patients, with a reasonable cost, is under development and may bypass some of these limitations for future trials [46]. This is particularly pertinent as the effect of this targeted energy feeding on physical and functional recovery remains unknown.

\section{Protein}

Inadequate protein provision has been considered a contributing factor explaining why RCTs, such as the EDEN trial mentioned earlier [3], do not show any beneficial impact of nutrition in the critically ill [47]. Early studies investigating protein intake in critically ill patients reported an improvement in whole-body nitrogen balance or whole-body protein turnover, with higher protein intakes [48]. Since then, several large observational studies have reported mortality benefits when higher protein delivery is achieved [49-51]. Whilst this may, in part, be because less sick patients may be able to have more protein delivered, this important confounder is accounted for in many of the more recent studies. For this reason, current recommendations range between 1.2 and $2.5 \mathrm{~g} / \mathrm{kg} /$ day [8]. Whilst it seems plausible that higher protein delivery may attenuate skeletal muscle loss, the data supporting 


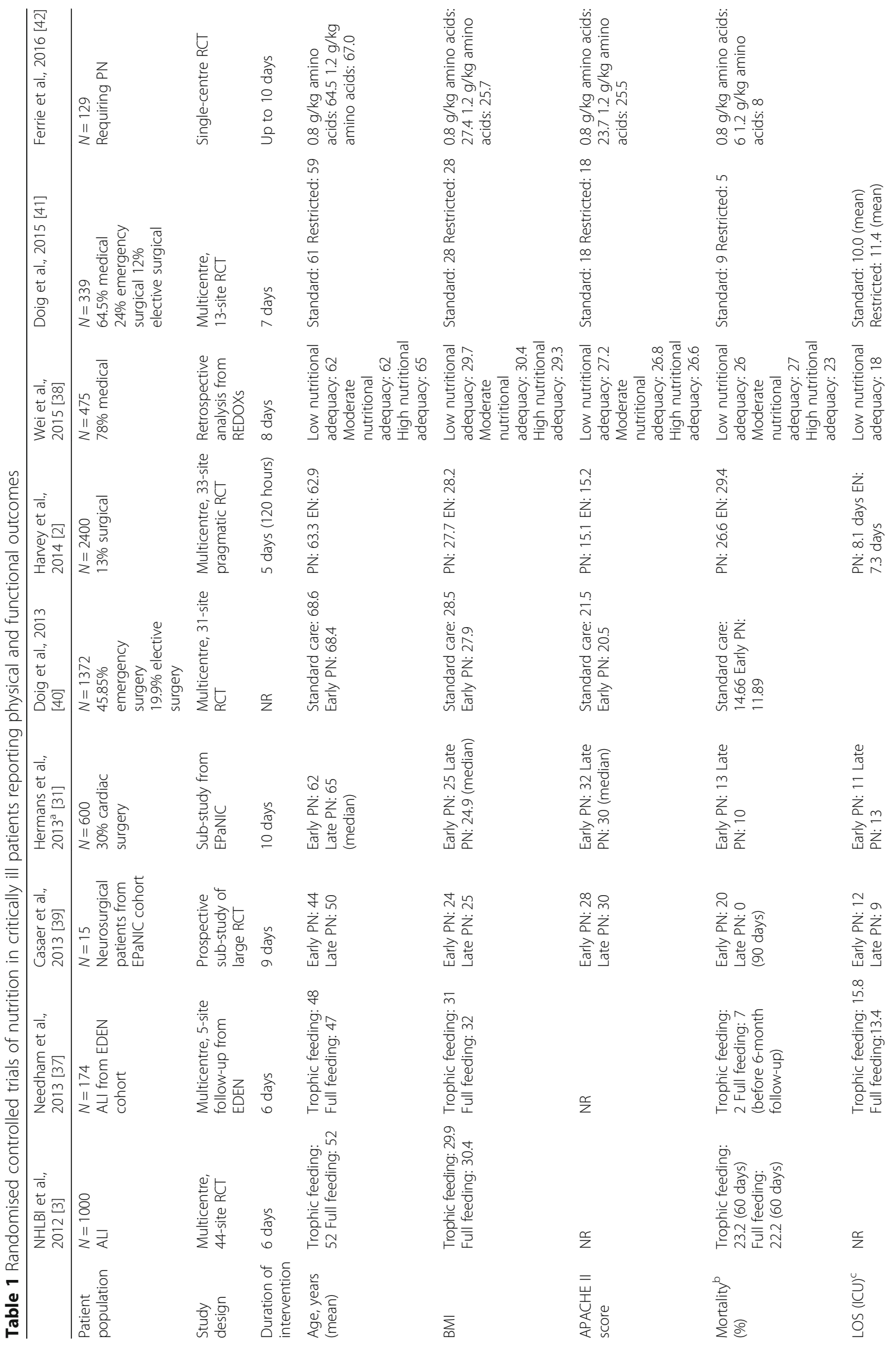




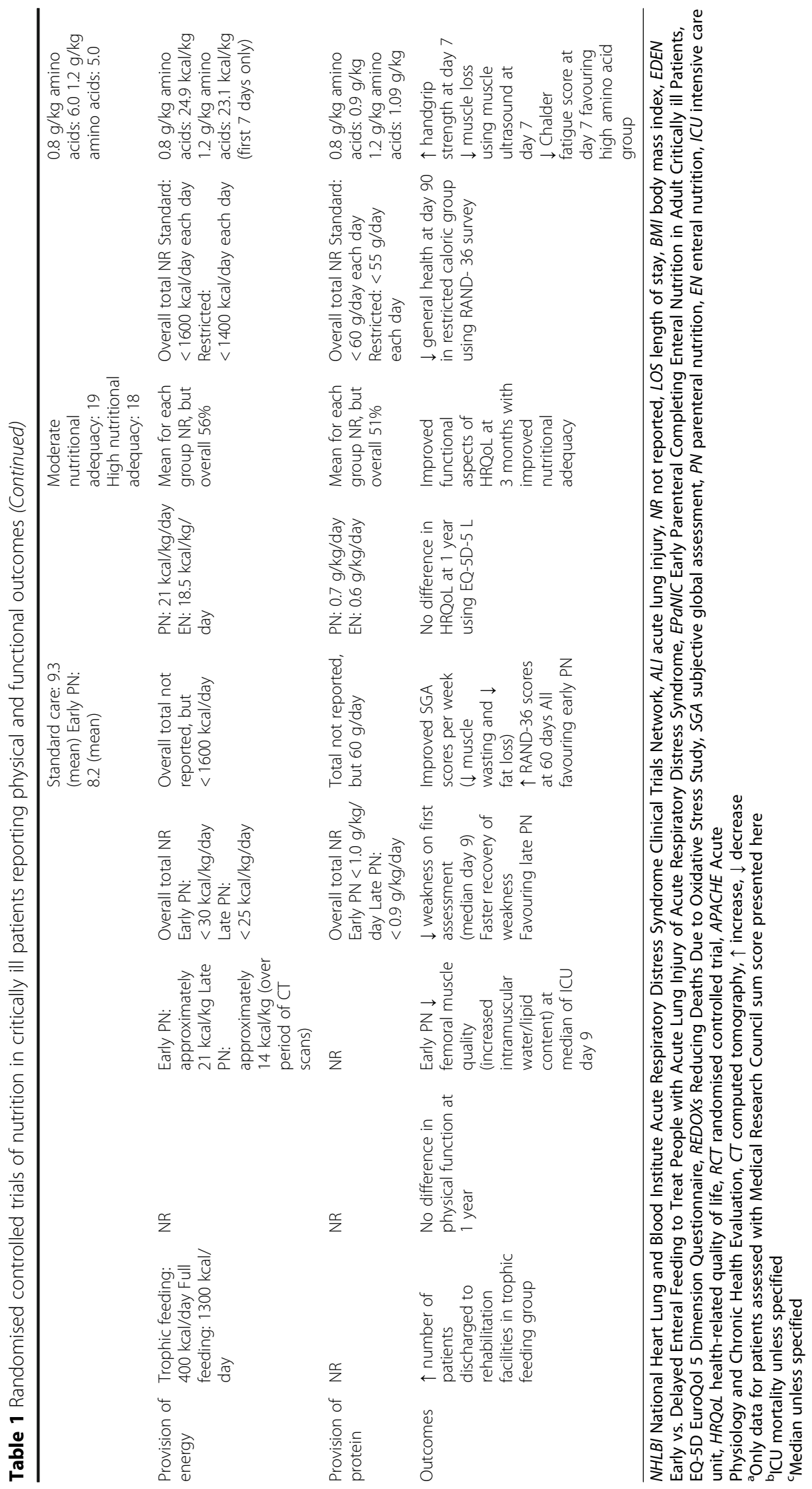


enhancement of muscle strength and function are lacking [52]. Secondary outcome results relating to the physical function component of the SF-36 score from the NephroProtective Trial [53], investigating the effect of intravenous amino acid supplementation on development of acute kidney injury, are awaited to contribute to the current evidence base.

One recent RCT investigated the effect of different protein intakes on muscle strength, wasting and fatigue in critically ill patients receiving PN [42]. In this study, 119 patients were randomised to receive 0.8 or $1.2 \mathrm{~g} / \mathrm{kg}$ protein. There was no difference in the primary outcome of handgrip strength at ICU discharge. However, despite a smaller than planned difference in the delivery of protein $(0.9 \mathrm{~g} / \mathrm{kg}$ vs $1.1 \mathrm{~g} / \mathrm{kg})$, the study found that a higher protein intake resulted in differences in secondary outcomes including greater handgrip strength at day 7, improved measures of forearm muscle thickness and rectus femoris cross-sectional area and reduced fatigue scores. These results support the concept that a higher protein intake, at least when supplied via the parenteral route, leads to a reduction in muscle wasting during the first week of critical illness. However, such preliminary findings await confirmation in larger studies that would, in particular, need to correct for baseline heterogeneity, as these results are in contrast to observational data from the EPaNIC Study [31, 39] and from the MUSCLE-UK group where higher protein delivery was observed to be associated with greater skeletal muscle wasting [16].

Taken together, these data have led to the hypothesis that it may not be the amount of protein delivered, but the way in which we deliver the feed in a continuous manner that drives skeletal muscle wasting [32]. In healthy subjects, muscle protein synthesis increases from 45 to 90 minutes after provision of amino acids, either oral or intravenous, but then decreases after 90 minutes $[54,55]$. This effect is observed despite the continued availability of amino acids in both the plasma and muscle, and has been termed the 'muscle full effect'. It is not unreasonable to consider that this effect is also relevant in critically ill patients, and this hypothesis underpins the rationale for the current multi-centre RCT comparing intermittent and continuous feeding to investigate the effect on skeletal muscle wasting [35].

\section{Methodological challenges}

\section{Patient selection}

One of the major challenges in demonstrating benefit from nutrition in critically ill patients is the heterogeneous nature of the clinical population. In this regard it is unlikely that all patients will benefit from the same treatment at the same time point. Whilst feeding protocols are recommended as a means of encouraging early enteral feeding, a 'one size fits all' approach to the treatment of critically ill patients is no longer considered appropriate. However, defining patients who are likely to benefit from a nutritional intervention will be challenging and will require rigorous investigation. One method currently suggested to distinguish those patients who may benefit from a targeted nutrition intervention from those who may not is the determination of nutrition risk. The most popular nutritional risk scoring systems for critically ill patients are the Nutrition Risk Score 2002 (NRS 2002) [56] and the Nutrition Risk in the Critically Ill (NUTRIC) score $[57,58]$. Although recent clinical trials have used the NRS 2002 in their inclusion criteria, this score may lack the specificity to determine the true nutrition risk of critically ill patients as an APACHE II score $>10$ automatically gives the highest risk score. Although the NUTRIC score was developed specifically for critically ill patients, it is yet to be validated prospectively. However, post-hoc analyses from the PermiT (The Permissive Underfeeding versus target Enteral Feeding in Adult Critically Ill Patients) trial did not show a mortality improvement when stratifying by this score [59]. In addition, these scoring systems do not include variables relating to muscle mass or baseline physical function therefore more work is required in the area of nutrition risk before it can be used as a criterion in future nutrition studies.

Potential tools for patient selection in clinical trials include those to determine both baseline skeletal muscle quantity and quality and change over time. Such tools include muscle ultrasound and CT. However, there are limitations with the use of these tools outside the research setting. First, there is currently no standardised, universal technique to perform muscle ultrasound [60]; and second, only patients who have required a CT scan for clinical purposes have been investigated, meaning that a selection bias may be present [61]. Nonetheless, with further work to standardise techniques, these measures may prove useful in the future either on their own or as an adjunct to existing nutrition risk tools. Lastly, if physical or functional outcomes are to be included as important clinical outcomes, then the limitations surrounding obtaining baseline measurements for nonelective ICU admissions will be equally as important and further work needs to be undertaken to understand this in detail.

\section{Delivery of the intervention}

Ensuring adequate delivery of the intervention is an essential factor in being able to interpret the outcome of such studies. Several studies in critical care nutrition have not been successful in reaching either target energy or protein delivery (Table 1) [2-4, 7, 40-42]. Notwithstanding that there may be physiological differences in the utilisation of substrates depending on the route and 
timing of nutrition delivery, strategies to enhance nutrition delivery $[62,63]$ should be factored into clinical trials where the outcome is dependent upon meeting a target.

\section{Duration of the intervention}

Biological plausibility is fundamental to any nutrition research. This includes the likelihood that an outcome will be observed at a particular time point as a result of the specified duration of an intervention. Effects from nutrition dosing are unlikely to be observed immediately and any effect will be reliant on the consistency of delivery of the intervention. For example, the EDEN trial reported no difference in physical outcomes at 1 year when trophic or full feeding was given for 6 days [37]. Given that current data suggest that oral intake is inadequate post extubation $[64,65]$ and in the post-ICU recovery phase [66], it may be unlikely that an effect would be observed 1 year after such a short intervention. Observational studies tend to include patients fed over a longer period of time and exclude those patients fed over shorter durations. Because of the risk of bias associated with the short duration of trials, we propose that critical care nutrition studies should continue for longer than the first week of critical illness and should consider post-ICU nutritional intake.

\section{Outcomes}

Whilst it is acknowledged that outcomes research is a priority for survivors of critical illness, no consensus exists on the most appropriate outcomes. There is considerable current activity in relation to core outcome sets in studies of physical rehabilitation [67] and long-term follow-up following acute respiratory failure [68] but no such initiative is ongoing for nutrition. Core outcome sets enable the combination and comparison of data from different studies of similar interventions and are urgently required in this field. Indeed, a recent scoping review of outcome measurement in ICU survivorship research from 1970-2013 found that 250 unique measurement instruments have been used across 425 studies [69]. Furthermore, only 31 RCTs included post-discharge outcomes and half of these had sample sizes of less than 100 subjects. Recent large trials undertaken in critical care nutrition have continued this pattern and utilised a variety of primary outcome measures from mortality to infectious complications and length of stay $[2-4,7,40,41,70]$. Whilst meta-analysis of such data is possible, the number of different outcome measures used profoundly limits the validity of any conclusions.

None of the large nutrition RCTs has used functional or health-related quality of life (HRQOL) measures as primary outcomes, but rather they have been included as secondary outcomes. This seems surprising, given that these are likely to be the outcomes where nutrition may show the most benefit [71], but reflects the current uncertainty regarding the most appropriate measure to use across the continuum of critical illness and recovery [14]. It is common that a significant number of patients are effectively excluded from recording of physical and functional ability due to either the volitional nature of the measure [72] or due to logistical issues with returning to follow-up appointments. Overall, these outcome measures can be labour intensive and expensive for the researcher, which may also impact on the choice of outcomes used for each study, the time points chosen to measure and the number of patients able to be followed up long term. Accounting for logistics and costs associated with measuring long-term outcomes is essential to the success of future trials.

\section{Recovery from critical illness}

There are few studies investigating nutritional support after the first week of critical illness. However, oral intake has been reported to be inadequate in patients following extubation [64, 65], regardless of the presence of enteral feeding [65]. Failure to meet nutritional targets following the first week of ICU stay and into the post-ICU phase may indeed negatively influence any long-term measurements of skeletal muscle mass and physical or functional ability, and may be a confounder in studies measuring these outcomes in recent clinical trials. In addition, postICU studies which have included varying degrees of nutrition intervention have shown conflicting results [73, 74] and therefore little is understood about the clinical effectiveness of these interventions in the post-ICU phase However, it is clear that this is a research priority [75].

Furthermore, the investigation of multi-modal interventions, coupling appropriate nutrition and exercise interventions at specific time points, is warranted given the physiological evidence that increases in muscle mass and improvements in exercise capability are stronger when these interventions are provided in tandem [15]. Indeed, a study investigating the effects of a combined nutrition and exercise intervention in the ICU is due to commence later this year [76]. The outcome of extending the combination of these two interventions in the post-ICU phase should also be investigated.

\section{Conclusion}

As survivorship after critical illness becomes an increasing focus of attention, future trials of nutrition during and following critical illness should consider specific factors that could provide measureable benefits in terms of both physical and functional recovery. Such factors include strategies to ensure adequate delivery of the intervention, provision of nutrition over a time frame in which it is biologically plausible to observe a difference in the desired outcome and selection of appropriate and 
consistent outcomes recorded at clinically relevant time points. Important outcomes include muscle mass, function and quality of life. In addition, patient selection of those most likely to benefit from nutritional interventions and nutrition research in the post-ICU phase merits specific attention.

\begin{abstract}
Abbreviations
ASPEN: American Society of Parenteral and Enteral Nutrition; CT: Computed tomography; EDEN: Early vs Delayed Enteral Feeding to Treat People with Acute Lung Injury or Acute Respiratory Distress Syndrome; EN: Enteral nutrition; EPaNIC: Early Parenteral Nutrition Completing Enteral Nutrition in Adult Critically III Patients; HRQOL: Health-related quality of life; ICU: Intensive care unit; MEE: Measured energy expenditure; MRC: Medical Research Council; MUSCLE UK: Musculoskeletal Ultrasound Study in Critical Care: Longitudinal Evaluation UK; NUTRIC: Nutrition Risk in the Critically III; PN: Parenteral nutrition; RCT: Randomised controlled trial; REDOXs: Reducing Deaths due to Oxidative Stress Study; SCCM: Society of Critical Care Medicine; SF-36: Short Form-36 health survey
\end{abstract}

\section{Acknowledgements}

DEB is funded by a Health Education England (HEE)/National Institute of Health Research (NIHR) ICA Clinical Doctoral Research Fellowship (ICA-CDRF-2015-01047). BC is funded by an NIHR Postdoctoral Fellowship (PDF-2015-08-015). DEB, $\mathrm{BC}$ and $\mathrm{NH}$ are supported by the NIHR Biomedical Research Centre based at Guy's and St Thomas' NHS Foundation Trust and King's College London. JLM is funded by a NHS Research Scotland (NRS) Fellowship. MPWG is supported by the Southampton NIHR Biomedical Research Centre based at University Hospital Southampton NHS Trust and the University of Southampton. The views expressed are those of the authors and are not necessarily those of the NHS, the NIHR or the Department of Health.

\section{Funding}

Not applicable.

\section{Availability of data and materials}

Not applicable.

\section{Authors' contributions}

All authors conceived of the idea. DEB, LW and JLM drafted the manuscript. $\mathrm{BC}$ assisted with design. All authors reviewed and commented on the manuscript and approved the final draft.

\section{Authors' information}

Not applicable.

Ethics approval and consent to participate

Not applicable.

\section{Consent for publication}

Not applicable.

\section{Competing interests}

DEB has received speaker fees and conference attendance support from Nutricia, Baxter, BBraun and Fresenius Kabi, and grant support through her institution from Corpak MedSystems UK. MPWG serves on the medical advisory board of Sphere Medical Ltd (UK) and is a director of Oxygen Control Systems Ltd (UK), and has received honoraria for speaking and/or travel expenses from Edwards Lifescience, Fresenius-Kabi, BOC Medical (Linde Group), Ely-Lilly Critical Care (2008) and Cortex GmBH. The remaining authors declare that they have no competing interests.

\section{Publisher's Note}

Springer Nature remains neutral with regard to jurisdictional claims in published maps and institutional affiliations.

\section{Author details}

'Department of Nutrition and Dietetics, Guy's and St Thomas' NHS Foundation Trust, London, UK. ${ }^{2}$ Department of Critical Care, Guy's and St
Thomas' NHS Foundation Trust, London, UK. ${ }^{3}$ Division of Asthma, Allergy, and Lung Biology, King's College London, London, UK. ${ }^{4}$ National Institute for Health Research (NIHR), Guy's and St Thomas' NHS Foundation Biomedical Research Centre, London, UK. ${ }^{5}$ Lane Fox Clinical Respiratory Physiology Research Centre, Guy's and St Thomas' NHS Foundation Trust, London, UK. ${ }^{6}$ Anaesthesia, Critical Care and Pain Medicine, University of Edinburgh, Royal Infirmary of Edinburgh, Edinburgh, UK. ${ }^{7}$ Centre for Human and Aerospace Physiological Sciences, King's College London, London, UK. ${ }^{8}$ Department of Physiotherapy, The University of Melbourne, Melbourne, VIC, Australia. IIntegrative Physiology and Critical IIIness Group, Clinical and Experimental Sciences, University of Southampton, Southampton, UK. ${ }^{10}$ Respiratory and Critical Care Research Theme, Southampton NIHR Biomedical Research Centre, Southampton, UK. ${ }^{11}$ Anaesthesia and Critical Care Research Unit, University Hospital Southampton NHS Foundation Trust, Southampton, UK.

Published online: 26 August 2017

\section{References}

1. Preiser JC, van Zanten AR, Berger MM, Biolo G, Casaer MP, Doig GS, Griffiths RD, Heyland DK, Hiesmayr M, lapichino G, et al. Metabolic and nutritional support of critically ill patients: consensus and controversies. Crit Care. 2015;19:35.

2. Harvey SE, Parrott F, Harrison DA, Bear DE, Segaran E, Beale R, Bellingan G, Leonard R, Mythen MG, Rowan KM, et al. Trial of the route of early nutritional support in critically ill adults. N Engl J Med. 2014;371(18):1673-84.

3. National Heart Lung and Blood Institute Acute Respiratory Distress Syndrome Clinical Trials Network, Rice TW, Wheeler AP, Thompson BT, Steingrub J, Hite RD, Moss M, Morris A, Dong N, et al. Initial trophic vs full enteral feeding in patients with acute lung injury: the EDEN randomized trial. JAMA. 2012;307(8):795-803.

4. Arabi YM, Aldawood AS, Haddad SH, Al-Dorzi HM, Tamim HM, Jones G, Mehta S, Mclntyre L, Solaiman O, Sakkijha MH, et al. Permissive underfeeding or standard enteral feeding in critically ill adults. N Engl J Med. 2015;372(25):2398-408.

5. Heyland D, Muscedere J, Wischmeyer PE, Cook D, Jones G, Albert M, Elke G, Berger MM, Day AG, Canadian Critical Care Trials Group. A randomized trial of glutamine and antioxidants in critically ill patients. N Engl J Med. 2013; 368(16):1489-97.

6. Rice TW, Wheeler AP, Thompson BT, deBoisblanc BP, Steingrub J, Rock P, $\mathrm{NIH} \mathrm{NHLBI}$ Acute Respiratory Distress Syndrome Network of Investigators. Enteral omega-3 fatty acid, gamma-linolenic acid, and antioxidant supplementation in acute lung injury. JAMA. 2011;306(14):1574-81.

7. Casaer MP, Mesotten D, Hermans G, Wouters PJ, Schetz M, Meyfroidt G, Van Cromphaut S, Ingels C, Meersseman P, Muller J, et al. Early versus late parenteral nutrition in critically ill adults. N Engl J Med. 2011;365(6):506-17.

8. McClave SA, Taylor BE, Martindale RG, Warren MM, Johnson DR Braunschweig C, McCarthy MS, Davanos E, Rice TW, Cresci GA, et al. Guidelines for the Provision and Assessment of Nutrition Support Therapy in the Adult Critically III Patient: Society of Critical Care Medicine (SCCM) and American Society for Parenteral and Enteral Nutrition (A.S.P.E.N.). JPEN. 2016;40(2):159-211.

9. McClave SA, Martindale RG, Rice TW, Heyland DK. Feeding the critically ill patient. Crit Care Med. 2014;42(12):2600-10.

10. Krezalek MA, Yeh A, Alverdy JC, Morowitz M. Influence of nutrition therapy on the intestinal microbiome. Curr Opin Clin Nutr Metab Care. 2017;20(2):131-7.

11. Cheung AM, Tansey CM, Tomlinson G, Diaz-Granados N, Matte A, Barr A, Mehta S, Mazer CD, Guest CB, Stewart TE. Two-year outcomes, health care use, and costs of survivors of acute respiratory distress syndrome. Am J Respir Crit Care Med. 2006;174(5):538-44.

12. Iwashyna TJ, Ely EW, Smith DM, Langa KM. Long-term cognitive impairment and functional disability among survivors of severe sepsis. JAMA. 2010; 304(16):1787-94.

13. Herridge MS, Tansey CM, Matte A, Tomlinson G, Diaz-Granados N, Cooper A, Guest CB, Mazer CD, Mehta S, Stewart TE. Functional disability 5 years after acute respiratory distress syndrome. N Engl J Med. 2011;364(14):1293-304.

14. Parry SM, Granger CL, Berney S, Jones J, Beach L, El-Ansary D, Koopman R, Denehy $L$. Assessment of impairment and activity limitations in the critically ill: a systematic review of measurement instruments and their clinimetric properties. Intensive Care Med. 2015;41(5):744-62.

15. Heyland DK, Stapleton RD, Mourtzakis M, Hough CL, Morris P, Deutz NE, Colantuoni E, Day A, Prado CM, Needham DM. Combining nutrition and 
exercise to optimize survival and recovery from critical illness: conceptual and methodological issues. Clin Nutr. 2016;35(5):1196-206.

16. Puthucheary ZA, Rawal J, McPhail M, Connolly B, Ratnayake G, Chan P, Hopkinson NS, Phadke R, Dew T, Sidhu PS, et al. Acute skeletal muscle wasting in critical illness. JAMA. 2013;310(15):1591-600.

17. Mira JC, Brakenridge SC, Moldawer LL, Moore FA. Persistent Inflammation, Immunosuppression and Catabolism Syndrome. Crit Care Clin. 2017;33(2): 245-58.

18. Puthucheary Z, Harridge $S$, Hart N. Skeletal muscle dysfunction in critical care. Wasting, weakness, and rehabilitation strategies. Crit Care Med. 2010; 38(10 Suppl):S676-82.

19. Weijs PJ, Looijaard WG, Dekker IM, Stapel SN, Girbes AR, Oudemans-van Straaten HM, Beishuizen A. Low skeletal muscle area is a risk factor for mortality in mechanically ventilated critically ill patients. Crit Care. 2014;18(2):R12.

20. Kreymann KG, Berger MM, Deutz NE, Hiesmayr M, Jolliet P, Kazandjiev G, Nitenberg G, van den Berghe G, Wernerman J, Ebner C. ESPEN Guidelines on Enteral Nutrition: intensive care. Clin Nutr. 2006;25(2):210-23.

21. Dhaliwal R, Cahill N, Lemieux M, Heyland DK. The Canadian critical care nutrition guidelines in 2013: an update on current recommendations and implementation strategies. Nutr Clin Pract. 2014;29(1):29-43.

22. McClave SA, Heyland DK. The physiologic response and associated clinical benefits from provision of early enteral nutrition. Nutr Clin Pract. 2009; 24(3):305-15.

23. Kudsk KA. Current aspects of mucosal immunology and its influence by nutrition. Am J Surg. 2002;183(4):390-8.

24. Heighes PT, Doig GS, Sweetman EA, Simpson F. An overview of evidence from systematic reviews evaluating early enteral nutrition in critically ill patients: more convincing evidence is needed. Anaesth Intensive Care. 2010;38(1):167-74.

25. Marik PE. Feeding critically ill patients the right 'whey': thinking outside of the box. A personal view. Ann Intensive Care. 2015;5(1):51.

26. Casaer MP, Van den Berghe G. Nutrition in the acute phase of critical illness. N Engl J Med. 2014;370(25):2450-1.

27. Kutsogiannis J, Alberda C, Gramlich L, Cahill NE, Wang M, Day AG, Dhaliwa R, Heyland DK. Early use of supplemental parenteral nutrition in critically ill patients: results of an international multicenter observational study. Crit Care Med. 2011;39(12):2691-9.

28. Villet S, Chiolero RL, Bollmann MD, Revelly JP, Cayeux RNM, Delarue J, Berger MM. Negative impact of hypocaloric feeding and energy balance on clinical outcome in ICU patients. Clin Nutr. 2005;24(4):502-9.

29. Dvir D, Cohen J, Singer P. Computerized energy balance and complications in critically ill patients: an observational study. Clin Nutr. 2006;25(1):37-44.

30. Heyland DK, Cahill N, Day AG. Optimal amount of calories for critically ill patients: depends on how you slice the cake! Crit Care Med. 2011;39(12):2619-26.

31. Hermans G, Casaer MP, Clerckx B, Güiza F, Vanhullebusch T, Derde S, Meersseman P, Derese I, Mesotten D, Wouters PJ, et al. Effect of tolerating macronutrient deficit on the development of intensive-care unit acquired weakness: a subanalysis of the EPaNIC trial. Lancet Respir Med. 2013;1(8):621-9.

32. Bear DE, Puthucheary Z. Potential nutritional strategies to reduce muscle wasting in early critical illness. ICU Management \& Practice. 2016;16(2):109-11.

33. Nguyen NQ, Chapman M, Fraser RJ, Bryant LK, Burgstad C, Holloway RH. Prokinetic therapy for feed intolerance in critical illness: one drug or two? Crit Care Med. 2007:35(11):2561-7.

34. Di Bartolomeo AE, Chapman MJAVZ, Summers MJ, Jones KL, Nguyen NQ, Rayner CK, Horowitz M, Deane AM. Comparative effects on glucose absorption of intragastric and post-pyloric nutrient delivery in the critically ill. Crit Care. 2012;16(5):R167.

35. McNelly A, Hart N. Intermittent versus continuous feeding in ICU patients (NCT02358512). 2015. www.clinicaltrials.gov. Accessed 5 Apr 2017

36. Cahill NE, Dhaliwal R, Day AG, Jiang X, Heyland DK. Nutrition therapy in the critical care setting: what is 'best achievable' practice? An international multicenter observational study. Crit Care Med. 2010:38(2):395-401.

37. Needham DM, Dinglas VD, Morris PE, Jackson JC, Hough CL, Mendez-Tellez PA, Wozniak AW, Colantuoni E, Ely EW, Rice TW, et al. Physical and cognitive performance of patients with acute lung injury 1 year after initial trophic versus full enteral feeding. EDEN trial follow-up. Am J Respir Crit Care Med. 2013;188(5):567-76.

38. Wei X, Day AG, Ouellette-Kuntz H, Heyland DK. The association between nutritional adequacy and long-term outcomes in critically ill patients requiring prolonged mechanical ventilation: a multicenter cohort study. Crit Care Med. 2015;43(8):1569-79.
39. Casaer MP, Langouche L, Coudyzer W, Vanbeckevoort D, De Dobbelaer B, Guiza FG, Wouters PJ, Mesotten D, Van den Berghe G. Impact of early parenteral nutrition on muscle and adipose tissue compartments during critical illness. Crit Care Med. 2013:41(10):2298-309.

40. Doig GS, Simpson F, Sweetman EA, Finfer SR, Cooper DJ, Heighes PT, Davies AR, O'Leary M, Solano T, Peake S, et al. Early parenteral nutrition in critically ill patients with short-term relative contraindications to early entera nutrition: a randomized controlled trial. JAMA. 2013;309(20):2130-8.

41. Doig GS, Simpson F, Heighes PT, Bellomo R, Chesher D, Caterson ID, Reade MC, Harrigan PW. Restricted versus continued standard caloric intake during the management of refeeding syndrome in critically ill adults: a randomised, parallel-group, multicentre, single-blind controlled trial. Lancet Respir Med. 2015;3(12):943-52.

42. Ferrie S, Allman-Farinelli M, Daley M, Smith K. Protein requirements in the critically ill: a randomized controlled trial using parenteral nutrition. JPEN. 2016;40(6):795-805.

43. Wischmeyer PE. Are we creating survivors ... or victims in critical care? Delivering targeted nutrition to improve outcomes. Curr Opin Crit Care. 2016:22(4):279-84

44. Reid CL. Poor agreement between continuous measurements of energy expenditure and routinely used prediction equations in intensive care unit patients. Clin Nutr. 2007;26(5):649-57.

45. Zusman O, Theilla M, Cohen J, Kagan I, Bendavid I, Singer P. Resting energy expenditure, calorie and protein consumption in critically ill patients: a retrospective cohort study. Crit Care. 2016;20(1):367.

46. Oshima T, Berger MM, De Waele E, Guttormsen AB, Heidegger CP, Hiesmayr M, Singer $P$, Wernerman J, Pichard C. Indirect calorimetry in nutritional therapy. A position paper by the ICALIC study group. Clin Nutr. 2017;36(3):651-62.

47. Wischmeyer P. Parenteral nutrition and calorie delivery in the ICU: controversy, clarity, or call to action? Curr Opin Crit Care. 2012;18(2):164-73.

48. Hoffer $\sqcup$, Bistrian BR. Appropriate protein provision in critical illness: a systematic and narrative review. Am J Clin Nutr. 2012;96(3):591-600.

49. Elke G, Wang M, Weiler N, Day AG, Heyland DK. Close to recommended caloric and protein intake by enteral nutrition is associated with better clinical outcome of critically ill septic patients: secondary analysis of a large international nutrition database. Crit Care. 2014;18(1):R29.

50. Allingstrup MJ, Esmailzadeh N, Wilkens Knudsen A, Espersen K, Hartvig Jensen $\mathrm{T}$, Wiis J, Perner A, Kondrup J. Provision of protein and energy in relation to measured requirements in intensive care patients. Clin Nutr. 2012;31(4):462-8.

51. Weijs PJ, Looijaard WG, Beishuizen A, Girbes AR, Oudemans-van Straaten HM. Early high protein intake is associated with low mortality and energy overfeeding with high mortality in non-septic mechanically ventilated critically ill patients. Crit Care. 2014;18(6):701.

52. Bear DE, Puthucheary ZA, Hart N. Early feeding during critical illness. Lancet Respir Med. 2014;2(1):15-7.

53. Doig GS, Simpson F, Bellomo R, Heighes PT, Sweetman EA, Chesher D, Pollock C, Davies A, Botha J, Harrigan P, et al. Intravenous amino acid therapy for kidney function in critically ill patients: a randomized controlled trial. Intensive Care Med. 2015:41(7):1197-208.

54. Bohe J, Low JF, Wolfe RR, Rennie MJ. Latency and duration of stimulation of human muscle protein synthesis during continuous infusion of amino acids. J Physiol. 2001;532(Pt 2):575-9.

55. Atherton PJ, Etheridge T, Watt PW, Wilkinson D, Selby A, Rankin D, Smith K, Rennie MJ. Muscle full effect after oral protein: time-dependent concordance and discordance between human muscle protein synthesis and mTORC1 signaling. Am J Clin Nutr. 2010;92(5):1080-8.

56. Kondrup J, Rasmussen $\mathrm{HH}$, Hamberg $\mathrm{O}$, Stanga $\mathrm{Z}$. Nutritional risk screening (NRS 2002): a new method based on an analysis of controlled clinical trials. Clin Nutr. 2003;22(3):321-36.

57. Heyland DK, Dhaliwal R, Jiang X, Day AG. Identifying critically ill patients who benefit the most from nutrition therapy: the development and initial validation of a novel risk assessment tool. Crit Care. 2011;15(6):R268.

58. Rahman A, Hasan RM, Agarwala R, Martin C, Day AG, Heyland DK. Identifying critically-ill patients who will benefit most from nutritional therapy: Further validation of the 'modified NUTRIC' nutritional risk assessment tool. Clin Nutr. 2016:35(1):158-62.

59. Arabi YM, Aldawood AS, Al-Dorzi HM, Tamim HM, Haddad SH, Jones G, Mclntyre L, Solaiman O, Sakkijha MH, Sadat M, et al. Permissive underfeeding or standard enteral feeding in high- and low-nutritional-risk critically ill adults. Post hoc analysis of the PermiT Trial. Am J Respir Crit Care Med. 2017;195(5):652-62. 
60. Sarwal A, Parry SM, Berry MJ, Hsu FC, Lewis MT, Justus NW, Morris PE, Denehy L, Berney S, Dhar S, et al. Interobserver reliability of quantitative muscle sonographic analysis in the critically ill population. J Ultrasound Med. 2015:34(7):1191-200.

61. Looijaard WG, Dekker IM, Stapel SN, Girbes AR, Twisk JW, Oudemans-van Straaten HM, Weijs PJ. Skeletal muscle quality as assessed by CT-derived skeletal muscle density is associated with 6-month mortality in mechanically ventilated critically ill patients. Crit Care. 2016;20(1):386.

62. Deane AM, Dhaliwal R, Day AG, Ridley EJ, Davies AR, Heyland DK. Comparisons between intragastric and small intestinal delivery of enteral nutrition in the critically ill: a systematic review and meta-analysis. Crit Care. 2013;17(3):R125.

63. Heyland DK, Dhaliwal R, Lemieux M, Wang M, Day AG. Implementing the PEP uP protocol in critical care units in Canada: results of a multicenter quality improvement study. JPEN. 2015;39(6):698-706.

64. Peterson SJ, Tsai AA, Scala CM, Sowa DC, Sheean PM, Braunschweig CL. Adequacy of oral intake in critically ill patients 1 week after extubation. $J$ Am Diet Assoc. 2010;110(3):427-33.

65. Rowles A, Langan A, Bear DE. SUN-P019: oral intake and appetite in the intensive care unit. Clin Nutr. 2016;35 Suppl 1:S51.

66. Chapple LS, Deane AM, Heyland DK, Lange K, Kranz AJ, Williams LT, Chapman MJ. Energy and protein deficits throughout hospitalization in patients admitted with a traumatic brain injury. Clin Nutr. 2016;35(6):1315-22.

67. Connolly B, Hart N, Williamson P, Blackwood B. Development of a core outcomes set for trials of rehabilitation following critical illness. 2013. http:// www.cometinitiative.org/studies/details/288?result=true. Accessed 5 Apr 2017.

68. Turnbull AE, Sepulveda KA, Dinglas VD, Chessare CM, Bingham 3rd CO, Needham DM. Core domains for clinical research in acute respiratory failure survivors: an international modified Delphi consensus study. Crit Care Med. 2017;45(6):1001-10.

69. Turnbull AE, Rabiee A, Davis WE, Nasser MF, Venna VR, Lolitha R, Hopkins RO, Bienvenu OJ, Robinson KA, Needham DM. Outcome measurement in ICU survivorship research from 1970 to 2013: a scoping review of 425 publications. Crit Care Med. 2016;44(7):1267-77.

70. Heidegger CP, Berger MM, Graf S, Zingg W, Darmon P, Costanza MC, Thibault R, Pichard C. Optimisation of energy provision with supplemental parenteral nutrition in critically ill patients: a randomised controlled clinical trial. Lancet. 2013;381(9864):385-93.

71. Arabi YM, Casaer MP, Chapman M, Heyland DK, Ichai C, Marik PE, Martindale RG, McClave SA, Preiser JC, Reignier J, et al. The intensive care medicine research agenda in nutrition and metabolism. Intensive Care Med. 2017. doi: 10.1007/s00134-017-4711-6

72. Connolly BA, Jones GD, Curtis AA, Murphy PB, Douiri A, Hopkinson NS, Polkey Ml, Moxham J, Hart N. Clinical predictive value of manual muscle strength testing during critical illness: an observational cohort study. Crit Care. 2013;17(5):R229.

73. Walsh TS, Salisbury LG, Merriweather JL, Boyd JA, Griffith DM, Huby G, Kean S, Mackenzie SJ, Krishan A, Lewis SC, et al. Increased hospital-based physical rehabilitation and information provision after intensive care unit discharge: The RECOVER Randomized Clinical Trial. JAMA Intern Med. 2015;175(6):901-10.

74. Jones C, Eddleston J, McCairn A, Dowling S, McWilliams D, Coughlan E, Griffiths RD. Improving rehabilitation after critical illness through outpatient physiotherapy classes and essential amino acid supplement: a randomized controlled trial. J Crit Care. 2015;30(5):901-7.

75. Latronico N, Herridge M, Hopkins RO, Angus D, Hart N, Hermans G, Iwashyna T, Arabi Y, Citerio G, Wesley Ely E, et al. The ICM research agenda on intensive care unit-acquired weakness. Intensive Care Med. 2017. doi:10.1007/s00134-017-4757-5.

76. Heyland DK. Nutrition and Exercise in Critical IIIness (NEXIS). (NCT03021902). 2016. www.clinicaltrials.gov. 